\title{
Comparative Study in Management of Serous Otitis Media Edical Management Versus Grommet Insertion
}

\author{
Dr. B. Nageswara Rao ${ }^{1}$, Dr.S.Surya prakasa Rao ${ }^{2}$, Dr.CH.S.V.S.Vikram ${ }^{3}$, Dr. \\ P. Jaya Geeta ${ }^{4}$ Dr.K.S.Raghu Chanakya ${ }^{5}$ \\ ${ }^{1}$ (Assistant Professor, Department Of ENT, Andhra Medical College, Vishakapatnam.) \\ ${ }^{2}$ (Professor, ENT,Andhra Medical College) \\ ${ }^{3}$ (Post Graduate Department Of ENT, Andhra Medical College ) \\ ${ }^{4}$ (Post Graduate Department Of ENT, Andhra Medical College) \\ ${ }^{5}$ (Post Graduate Department Of ENT, Andhra Medical College)
}

\begin{abstract}
:
Aims of the study:

1. To assess the best line of treatment for serous otitis media.

2. To prevent the complications of serous otitis media.

Materials And Methods: In Andhra medical college Government ENT hospital, a Tertiary referral hospital in Andhra Pradesh, a total of 56,800 patients were examined from January 2014 to December 2015 i.e. in 24 months period. 260 cases of serous otitis media, with hard of hearing, aural fullness, pain in the ear and tinnitus were identified for this study. Finally 60 cases of persistent serous otitis media after 1 month of medical management were selected. They were divided into 2 groups each with 30 patients. In Group I, the medical management was continued for 6 months. In Group II, the grommet was inserted in anterior inferior quadrant. The sex predominance, incidence in age group, etiological factors and its complications are analyzed at the end of 6 months. Comparative study of Audiological assessment was not included.

Conclusion: In this study, Adenoid Hypertrophy was found to be the commonest cause of serous otitis media in the age group of 6-15 years. It was observed that grommet should be inserted in serous otitis media not responding to one month of medical treatment. If they are prolonged with medical management, complications like, retraction of different grades to adhesive otitis media and chronic suppurative otitis media with either sinus cholesteatoma or attic cholesteatoma will precipitate. Tympanosclerosis of Tympanic membrane was found to be equally developing in patients with medical management and also in grommet insertion.
\end{abstract}

Keywords: Serous Otitis Media, Grommet, Conductive hearing loss, Adhesive otitis media, Tympanosclerosis.

\section{Introduction}

Serous otitis media both in children and adults is a challenging problem to the ENT surgeon, which is due to adenoiditis, rhinosinusitis, nasal allergy, deviated nasal septum, benign and malignant obstructive mass lesions of the nose and rarely due to radiation and cleft palate ${ }^{1}$. The neglected serous otitis media is the second commonest cause of adhesive otitis media, the first being allergic rhinosinusitis. In some patients with serous otitis media, spontaneous recovery is also observed. ${ }^{2}$ In children, the commonest cause is being rhinitis with adenoiditis, hence we should combine adenoidectomy also in the treatment of serous otitis media. Chronic allergic rhinosinusitis found to be the commonest cause of serous otitis media in adults, hence Functional Endoscopic Sinus Surgery has to be combined if necessary. In nasal allergy, the need of regular and prolonged usage of oral anti histaminics and local nasal corticosteroid sprays ${ }^{3}$ should be insisted to the patients which when commonly neglected ends up with recurrence of both chronic allergic rhinosinusitis and serous otitis media. The rare cause of serous otitis media is the malignancies of nasopharynx which should always be suspected particularly in elderly age group i.e. above 50 years with history of exposure to saw dust and smoking. In children in the age group of 5 to 10 years, the commonest cause of deafness is being the serous otitis media, the parents and teachers of the schools should be kept aware of the possibilities. Children with nasal discharge who are listening with high volumes of intensity in radio and TV are strongly suspected.

In the present day, the number of air travelers, stay in resorts at higher altitudes, swimming and water sports including underwater diving are increasing ${ }^{4}$, which also can give rise to serous otitis media.

Complications of serous otitis media can be avoided if they are diagnosed in early stage. The most common complication is adhesive otitis media. Few cases may end up with either sinus cholesteatoma or attic cholesteatoma. These cholesteatoma cases produce continuous discharge, hard of hearing which are major problems in day to day life. Some cases of cholesteatoma may result in further grave situations like both extracranial and intracranial complications. Commonest extracranial complications are mastoid abscess, 
labrynthitis and rare intracranial complications are meningitis, extradural abscess, cerebral and cerebellar abscesses.

It is observed that Tympanosclerosis and Sudden sensorineural hearing loss are associated with serous otitis media in few cases. Sudden Sensorineural hearing loss can be explained by the toxic labrynthitis associated with serous otitis media of viral etiology.

The regular checkup in children by their family pediatrician has to be stressed and also school health checkups should include thorough examination of ENT area and audiometry with interval of 6 months.

All the cases of serous otitis media are primarily treated by medical line of management and treating the etiological factor. In cases of persisting otitis media, Grommet is inserted by different group of surgeons at different intervals after medical management. ${ }^{5,6,7}$

\section{Materials And Methods}

This retrospective study was conducted in a tertiary referral hospital in Visakhapatnam Government E.N.T Hospital, Andhra medical college from January 2014 to December 2015 for about 24 months.

56,800 out patients attended to Govt.E.N.T.Hospital during the study period. Among them, 21,590 patients complained hard of hearing with or without ear discharge.

3,200 patients with hard of hearing without ear discharge were identified. These patients also complained of aural fullness, autophony, tinnitus, pain in the ear, nasal discharge, nasal obstruction and mouth breathing. They are associated with adenoiditis, nasal allergy with sinusitis, deviated nasal septum and rarely other nasal obstructive lesions.

260 patients were diagnosed as serous otitis media and they were examined by Bull's eye lamp, Otoendoscope and Microscope. Hb, TC, DC, ESR, Absolute eosinophil count, X ray of Mastoids, PNS and lateral view of nasopharynx for adenoids were done and CT PNS when indicated. Pure tone audiometry, impedence audiometry performed and the type of deafness, amount of air bone gap and middle ear compliance are noted.

\section{Inclusion criteria:}

1. Serous otitis media in the age group of $6-55$ years.

Exclusion criteria:

1. Audiological analysis.

2. Haemotympanum.

3. Radiation induced serous otitis media.

4. Cleft palate.

5. Malignant lesions of nose and nasopharynx.(there is overlapping of serous otitis media and radiation complications)

Conventional medical management which included antibiotics ${ }^{8} \mathrm{Tab} /$ Syrup Amoxycillin, Cefixime, Tab Cetrizine, Tab Phenylephrine, Tab Ambroxyl and Xylometazoline nasal decongestants, were prescribed and steam inhalations were advised. All the cases were followed for one month and among them, those cases with serous otitis media still persisting were selected for our study.

All the above cases were treated for etiological factors by adenoidectomy ${ }^{9,10}$, Functional Endoscopic Sinus Surgery, Septoplasty and continued with treatment for allergy if present with antihistaminic Levocetrizine and Fluticasone nasal spray regularly. This gives correct comparison between prolonged medical management versus grommet insertion in persisting serous otitis media after 1 month of medical management.

60 patients with persisting serous otitis media after one month duration with medical management were selected for this study. They were divided into two groups, each group consisting of 30 patients.

Group I patients were continued with medical management extending upto 6 months and the complications are noted.

In Group II Tympanotomy and insertion of grommet was performed in children under general anaesthesia and in adults under local anaesthesia. In all the cases the grommet is positioned at antero-inferior quadrant. All the cases were reviewed after $2^{\text {nd }}$ month, $4^{\text {th }}$ month and at the end of 6 months, the complications and extrusion of the grommet were noted.

The study was aimed at sex predominance, Age distribution, etiological factors and complications at the end of $2^{\text {nd }}, 4^{\text {th }}$ and 6 months. Study of audiological assessment was not included here.

\section{Observation and results:}

The total number of patients examined from January 2014 to December 2015 was 56,800. Among them, 21,590 patients (38.01\% in total patients that attended OP) attended with hard of hearing with or without 
ear discharge. 3,200 patients (14.8\% in patients with ear symptoms) presented with hard of hearing without ear discharge and with aural fullness, autophony, tinnitus, nasal stuffiness, nasal discharge and sneezing.

All the cases were treated for etiological factors by adenoidectomy, Functional Endoscopic Sinus Surgery, Septoplasty and treatment for allergy is continued if present.

260 patients $(1.2 \%$ in patients with ear symptoms) with serous otitis media were identified and conventional medical treatment given for 1 month and reviewed after 1 month. 44 Patients (22\% in patients with serous otitis media) have not attended for follow up. In the rest of 156 patients, 88 patients (44\% in patients with serous otitis media) were relieved from serous otitis media and 4 patients ( $2 \%$ in patients with serous otitis media) developed Grade 1, mild retraction of tympanic membrane.

Rest of the 64 cases (32\%) with persisting serous otitis media after 1 month of medical management were divided into two groups. Group I with 32 cases were continued conventional management for 3 months. Group II with 32 cases, grommet insertion was performed and observed for 6 months ${ }^{11}$. Total 4 patients have not attended for follow up which consists 2 from Group I and 2 from Group II.

Thus the final study has 60 patients. Group I consists of 30 patients and Group II consists of 30 patients.

\begin{tabular}{|l|l|}
\hline Group I & 30 \\
\hline Group II & 30 \\
\hline
\end{tabular}

\section{Sex distribution:}

\begin{tabular}{|l|l|l|}
\hline SEX & INCIDENCE & PERCENTAGE \\
\hline Males & 36 & $60 \%$ \\
\hline Females & 24 & $40 \%$ \\
\hline
\end{tabular}

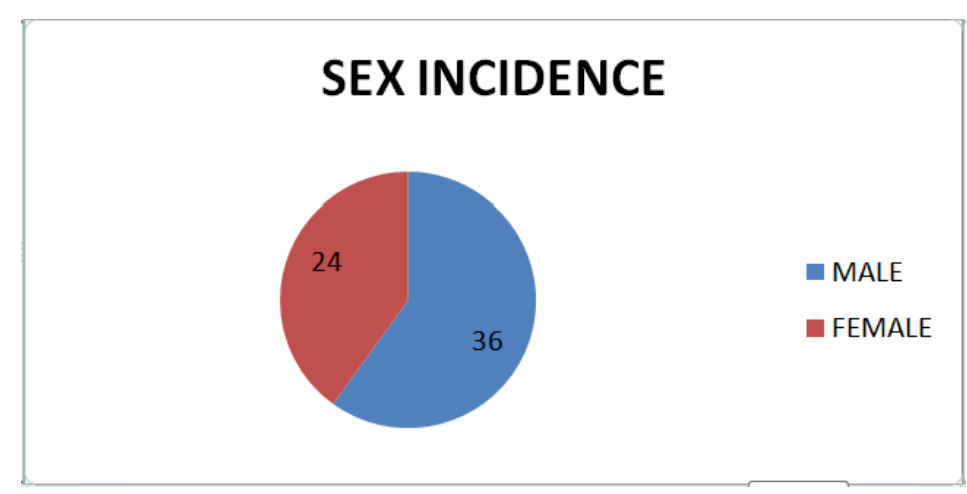

Among the study group which consisted of 60 patients, 36(60\%) were males and 24(40\%) were females showing male predominance.

\section{Age distribution:}

\begin{tabular}{|l|l|}
\hline Age Group In Years & Incidence \\
\hline $6-15$ & 32 \\
\hline $16-25$ & 11 \\
\hline $26-35$ & 9 \\
\hline $36-45$ & 5 \\
\hline $46-55$ & 3 \\
\hline
\end{tabular}

In the above study, age group of 6-15 years(53.3\%) was effected

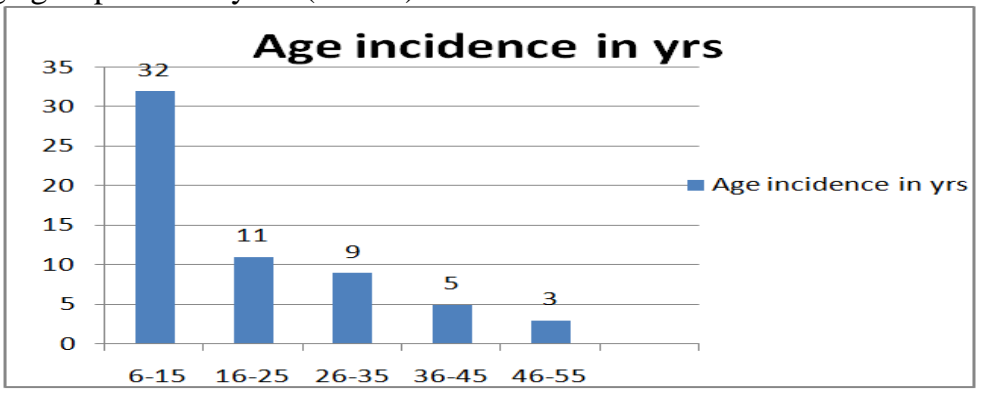

most commonly later is the $16-25$ years age group $(18.33 \%)$ and the least effected is 46-55 years age group (5\%). 
Etiological factors:

\begin{tabular}{|l|l|}
\hline Adenoid Hypertrophy & 28 \\
\hline Nasal allergy with Sinusitis & 21 \\
\hline Deviated Nasal Septum with NA & 6 \\
\hline Swimming & 2 \\
\hline Air Travel & 2 \\
\hline Unknown & 1 \\
\hline
\end{tabular}

The adenoid hypertrophy(46.6\%) was found to be the most common cause of Serous otitis media next is the nasal allergy with rhinosinusitis (35\%) later is the Deviated Nasal Septum with nasal allergy.(10\%) Swimming and Air travel (3.33\%) were the rarest causes of Serous otitis media. ${ }^{1}$

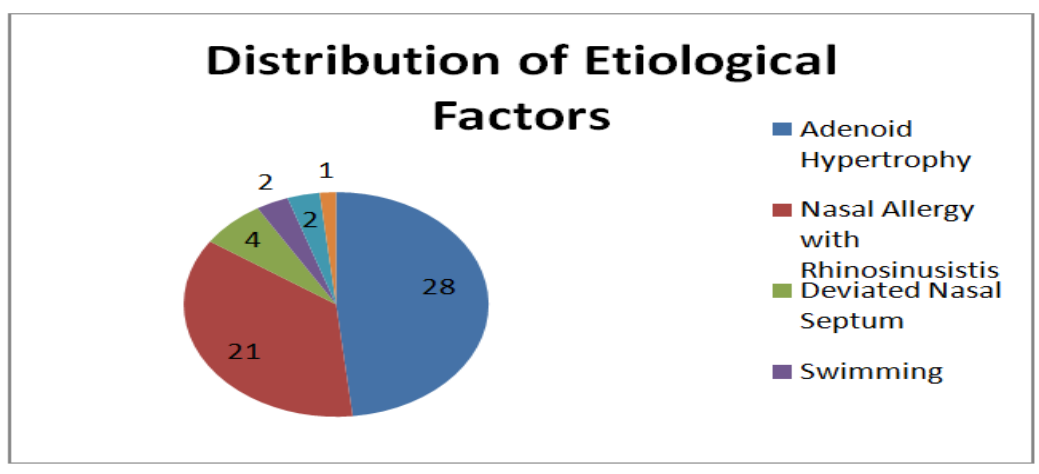

Complications observed in the follow up:

Group-i medical management.

Group ii - grommet insertion.

\begin{tabular}{|c|c|c|c|}
\hline Group & $2^{\text {nd }}$ month & $4^{\text {th }}$ month & $6^{\text {th }}$ month \\
\hline I & $\begin{array}{l}\text { 4- Grade } 1 \text { Retraction. } \\
\text { 1- Grade } 2 \text { Retraction. }\end{array}$ & $\begin{array}{l}\text { 9- Grade } 1 \text { Retraction } \\
\text { 4- Grade } 2 \text { Retraction } \\
\text { 1- Grade } 3 \text { Retraction } \\
\text { 1- Sinus Cholesteatoma }\end{array}$ & $\begin{array}{l}\text { 5-Grade } 1 \text { Retraction } \\
\text { 8-Grade } 2 \text { Retraction } \\
\text { 3-Grade } 3 \text { Retraction } \\
\text { 2-Grade } 4 \text { retraction } \\
\text { 3-Sinus cholesteatoma } \\
\text { 2-Attic cholesteatoma } \\
\text { 1- Persisting SOM } \\
\text { 4- Disease free with normal } \\
\text { tympanic membrane } \\
\text { 2-Tympanosclerosis of tympanic } \\
\text { memberane }\end{array}$ \\
\hline II & All grommets are in situ & $\begin{array}{l}\text { 14- Grommets extruded } \\
\text { 16- Grommets are in situ. }\end{array}$ & $\begin{array}{l}\text { 26- Grommets extruded with } \\
\text { normal tympanic membrane. } \\
\text { 2- Grommets in situ. } \\
\text { 2-Grommets extruded but with } \\
\text { Tympanosclerosis. }\end{array}$ \\
\hline
\end{tabular}

\section{Discussion}

This study shows that the age group of 6-15 is commonly affected (53.3\%) which proves that Rhinitis with Adenoid Hypertrophy is the commonest cause of serous otitis media.

In this study, Group I patients where the medical treatment is prolonged for 6 months (in persisting serous otitis media after one month of medical management) have mostly developed complications. In those at the end of 6 months the Grade- 2 retraction, tympanic membrane touching the incus is the commonest complication developed in 8 patients(26.6\%), later are Grade-1 mild retraction in tympanic membrane in 5 cases $(16.6 \%)$, Grade-3 retraction, tympanic membrane touching the promontory but still mobile in 3 cases $(10 \%)$, sinus cholesteatoma 3 cases (10\%), Grade-4, tympanic membrane plastered to promontory in 2 cases $(6.6 \%)$ and attic cholesteatoma in 2 cases $(6.6 \%)$.

In 1 case $(3.3 \%)$ there was still persisting serous otitis media continued and 4 cases(13.4\%) were totally found disease free with normal tympanic membrane with cone of light present in the antero-inferior quadrant and in 2 patients (6.6\%) Tympanosclerosis of Tympanic memberane was observed.

In Group II, Tympanotomy and insertion of grommet in anteroinferior quadrant which is a safe quadrant, was performed in children under general anaesthesia and in adults under local anaesthesia.

In the Group II where the grommet is inserted in persisting serous otitis media after one month of conventional medical management, at the end of 6 months period, 26 patients $(86.8 \%)$ totally recovered from 
serous otitis media with attaining normal tympanic membrane, and 2 patients $(6.6 \%)$ were still have grommets in situ without middle ear effusion. ${ }^{11}$ In 2 patients(6.6\%) Tympanosclerosis of tympanic membrane developed but the grommet is extruded ${ }^{12}$.

These observations suggests that grommet insertion is essentially considered in persisting serous otitis media after one month of medical management, to prevent the complications like retraction in different grades which produce hard of hearing and formation of cholesteatoma commonly either sinus cholesteatoma or attic cholesteatoma.

Cholesteatoma is a challenging problem which produces discharging ear with deafness and further complications of extracranial and grave intracranial. The surgery for cholesteatoma which include tympanoplasty with mastoidectomy( cortical, modified radical and radical) which itself again may produce complications and recurrence of cholesteotoma with Chronic Suppurative Otitis media.

In both Group 1 and Group 2, Tympanosclerosis of Tympanic memberane was found equally in 2 patients, showed that the incidence is same in both types of management i.e., medical management and grommet insertion.

In 2 cases out of total serous otitis media of total out patients had developed sensorineural deafness within the first week of disease. After thorough further investigations other etiological factors excluded and the possibility of viral toxic labyrinthitis is diagnosed.

\section{Conclusion}

In this study, serous otitis media is affected most commonly in 6-15 years age group which is due to Rhinitis with Adenoid hypertrophy. The study indicates that the insertion of grommet should be considered in all the cases of persistent serous otitis media after one month of medical management, to prevent adhesive otitis media with different grades of retraction and cholesteatoma either in attic or sinus tympani. These complications further deteriorate hearing and produce discharging ear.

Tympanosclerosis of Tympanic membrane is equally developed in both Groups of medical management and grommet insertion.

Thus prevention is better than cure, hence early grommet insertion is better in serous otitis media than continuing medical management which may end in more complications and surgeries like tympanoplasty or mastoidectomy.

Hence the need of detection of serous otitis media at the earliest by family physician in regular health check-ups and pediatrician in regular school health camps is stressed.

\section{References}

[1]. The etiology of glue ear in a case control study. Int.J Pediatr otorhinolaryngol 1985; 9:121-33.

[2]. Tos M epidemiology and spontaneous improvement of secretory otitis.Acta Otorhinolaryngol Belg 1983;37:43

[3]. Simpson SA, Lewis R, van der Voort J, Butler CC. Oral or topical nasal steroids for hearing loss associated with otitis media with effusion in children. Cochrane Database Syst Rev. 2011;(5): CD001935.

[4]. Becker GD, Eckberg TJ, Goldwar RR, Swimming and Tympanostomy tube; A prospective study. Laryngoscope 1987;97:740-1.

[5]. Rosenfeld RM, Schwartz SR, Pynnonen MA, et al. Clinical practice guideline: tympanostomy tubes in children. Otolaryngol Head Neck Surg. 2013;149(suppl 1):S1-S35pmid:23818543

[6]. Hellström S, Groth A, Jörgensen F, et al. Ventilation tube treatment: a systematic review of the literature. Otolaryngol Head Neck Surg. 2011;145(3):383-395pmid:21632976.

[7]. Browning GG, Rovers MM, Williamson I, Lous J, Burton MJ. Grommets (ventilation tubes) for hearing loss associated with otitis media with effusion in children. Cochrane Database Syst Rev. 2010;(10):CD001801.

[8]. Van Zon A, van der Heijden GJ, van Dongen TM, Burton MJ, Schilder AG. Antibiotics for otitis media with effusion in children. Cochrane Database Syst Rev. 2012;9:CD009163pmid:22972136.

[9]. Van den Aardweg MT, Schilder AG, Herkert E, Boonacker CW, Rovers MM. Adenoidectomy for otitis media in children. Cochrane Database Syst Rev. 2010;(1):CD007810.

[10]. Widemar L Sevensson C, Rhymel-Dagoo B,Schiratzki H. The effect of adenoidectomy on secretory otitis media

[11]. Brown MJ, Richards SH, Ambregookar Ag, Grommets and glue ear. A five year follow up of a controlled trial. JR Soc Med 1978;71:353-6.

[12]. James Mason,George Browning,Nick Freemantle.British Medical Journal 2001;323:1096 